\title{
ITINERARIOS ANTROPOLÓGICOS PARA UNA ETNOHISTORIA COMPARADA DE LA RELIGIÓN: CULTOS CATÓLICOS AMERICANOS EN LA LARGA DURACIÓN
}

\author{
ANTHROPOLOGICAL ITINERARIES FOR A COMPARATIVE ETHNOHISTORY \\ OF RELIGION: CATHOLIC CULTS IN THE LONG DURATION
}

\begin{abstract}
Julia Costilla*
Este artículo propone una reflexión respecto de las posibilidades y desafíos de la etnohistoria a base de una investigación concreta acerca de cultos católicos hispanoamericanos, partiendo de su inserción en un marco académico particular-Instituto de Antropología de la Universidad de Buenos Aires- y de su posición disciplinar entre la etnohistoria y la antropología de la religión. Siguiendo distintos ejes -preguntas de investigación, marco geográfico, dimensión temporal y unidades de análisis-analizaremos los objetivos, recortes y métodos de la investigación en términos de cambios y continuidades en el desarrollo de la etnohistoria, especialmente en el ámbito argentino. De esta manera, dentro de su particular contexto institucional y disciplinar, la investigación aquí analizada quedará planteada como propuesta de un horizonte posible dentro de la etnohistoria hispanoamericana.
\end{abstract}

Palabras claves: Etnohistoria, antropología de la religión, práctica profesional, catolicismo latinoamericano.

This article proposes a reflection on ethnohistory's possibilities and challenges, considering a specific research on HispanicAmerican catholic cults which was developed in a particular academic framework (Institute of Anthropology, Buenos Aires University) and in a singular position between ethnohistory and anthropology of religion. Following different axes -research questions, geographical framework, temporal dimension and units of analysis-I will analyze the goals, cutbacks and methods of that research in terms of changes and continuities in ethnohistory development, particularly in Argentina. In this way, within their institutional and disciplinary context, that research will set out as a possible horizon in the Hispanic-American ethnohistory. Key words: ethnohistory, anthropology of religion, professional practice, Latin-American Catholicism.

\section{Introducción}

En los últimos cinco años realizamos con un equipo dentro de la Sección Etnohistoria de la UBA (Universidad de Buenos Aires, Facultad de Filosofía y Letras, Instituto de Ciencias Antropológicas) una indagación acerca de la etnohistoria argentina y una compilación respecto de los estudios andinos (Zanolli et al. 2010; Zanolli et al., comps. 2013). Para quienes integramos el equipo esto actuó como disparador para repensar nuestro lugar como etnohistoriadores dentro del campo académico actual -a nivel local, nacional y regional-y al mismo tiempo como estudiosos de "lo andino". Partiendo de reconocer la permanente y necesaria articulación entre intereses personales $\mathrm{y}$ condicionamientos académicos e institucionales, en este trabajo me propongo analizar una investigación concreta -aquella que he desarrollado como tesis doctoral- en relación a esa peculiar articulación. Consideraré entonces las circunstancias (metodológicas, teóricas, operativas, estratégicas, etc.) bajo las cuales se fue configurando en un particular contexto institucional y disciplinar.

La investigación a la cual nos referiremos, titulada Luchas hermenéuticas, identidades y usos estratégicos del milagro en la elaboración y apropiación de cultos cristianos americanos (siglos XVII a XXI-Perú, Bolivia y Argentina), ha tenido como propósito principal realizar un seguimiento diacrónico y comparativo de los procesos que atravesaron distintos cultos católicos americanos, tomando un amplio período histórico. Para ello se eligieron tres casos paradigmáticos: la Virgen de Copacabana en la localidad homónima (Bolivia), el Señor de los Milagros en Lima (Perú) y la Virgen del Rosario en San Nicolás de los Arroyos (Argentina), seleccionados sobre la base de varios criterios acerca de los cuales no nos extenderemos aquí ${ }^{1}$. Tanto el caso de Copacabana como el de Lima nos remitieron a orígenes coloniales (siglos XVI y XVII, respectivamente); mientras que el de San Nicolás, con su

* Universidad de Buenos Aires, Facultad de Filosofía y Letras, Sección Etnohistoria. Buenos Aires, Argentina. Correo electrónico: juliacostilla@hotmail.com 
origen en 1983, correspondía a un contracaso por su alejamiento temporal y espacial.

Para la reflexión se propone tomar en cuenta cuatro ejes que se abordarán de manera separada: preguntas de investigación, marcos espaciales, dimensión temporal y unidades de análisis. En cada uno de ellos se expondrán algunos ejemplos específicos que permitan ilustrar la tensión entre adscribir a determinadas tradiciones académicas y romper con prácticas previas, y al mismo tiempo abrir la discusión acerca de la pertinencia de ciertas elecciones teórico-metodológicas. De esa manera, se propone revisar críticamente el lugar de esta investigación como horizonte posible dentro de la etnohistoria latinoamericana.

\section{Las preguntas de investigación}

Si la etnohistoria puede ser entendida como una investigación de tipo histórica guiada por "preguntas antropológicas" (Sturtevant 1966; Zanolli et al. 2010), en este punto interesa reflexionar respecto de la especificidad antropológica de las preguntas que guiaron la indagación.

En principio, tratándose de una investigación enfocada en sistemas de creencias, símbolos y rituales en la construcción de identidades sociales, las temáticas elegidas pueden ser entendidas como propiamente antropológicas; cruzadas, a su vez, con una problemática histórica concreta: las relaciones entre sistemas religiosos a partir de la colonización hispana. En el ámbito académico local, esta propuesta entroncaba con un tema tradicional en el marco de un proyecto etnohistórico institucional (la historia colonial de las sociedades americanas), pero definiendo un camino singular, orientado hacia la problemática religiosa. Si bien el equipo ya contaba con estudios vinculados al orden de lo simbólico y a los rituales (cfr. Boixadós 1994; Ortemberg 2000; Smietnianski 2007) ${ }^{2}$, estos se planteaban en mayor medida vinculados al ejercicio del poder y no abordaban particularmente las prácticas religiosas. Al mismo tiempo, la investigación propuesta se sumaba a una línea de trabajos centrados en los agentes eclesiásticos (Avellaneda 1999; Estruch 2008; Quarleri 1999; Wilde 2003).

A diferencia de esas líneas previas, proponemos enfocar la problemática del símbolo y su polisemia a partir del estudio comparado de cultos a imágenes cristianas milagrosas, planteando como hipótesis inicial la posibilidad de tomar al milagro como símbolo religioso. Dentro de los objetivos generales, uno de ellos podría caracterizarse como histórico y el otro como de carácter más antropológico: el primero fue analizar comparativamente el desarrollo histórico de los cultos contemplando cambios y continuidades; el segundo, analizar cómo opera el milagro cristiano en la dinámica social, considerando especialmente cuál es su lugar -y el de la religión en general- en los procesos ligados a la integración social y a la construcción de identidades. De esta forma, uno de los interrogantes guía fue desde qué lugares se construyó el milagro cristiano y con qué objetivos ha sido esgrimido dentro del contexto hispanoamericano: en qué medida intervino en la consolidación de los cultos y en los procesos de comunalización (Brow 1991) orientados a la conformación de sentidos de pertenencia.

Salvo algunas excepciones, y más allá de ser reconocido su papel clave en el proceso de evangelización (Gruzinski 1991; Rostworowski 1992; entre otros), en la tradición etnohistórica el milagro no había sido enfocado como objeto de un análisis antropológico. Sí analizaron su intervención en el proceso de conquista y colonización investigadores como Bouysse-Cassagne (1997) y Estenssoro (2003, 2005). En general, la etnohistoria ha demostrado un interés en el estudio de cultos religiosos para reconstruir las dinámicas culturales que acompañaron la incorporación de las poblaciones americanas al catolicismo (p. ej. Lorandi y Schaposchnik 1990); incluso para analizar la estructuración de religiosidades locales (Christian 1991) entre las poblaciones indígenas -a partir de una interpretación del cristianismo vinculada a un proyecto evangelizador y a la reapropiación de las religiosidades castellanas(Hidalgo et al. 2013). También se emprendieron estudios acerca de imágenes religiosas apropiadas desde distintos sectores de la sociedad colonial (cfr. Mujica 2001). Pero la propuesta apuntó a un análisis etnohistórico focalizado en la trayectoria histórica de cultos específicos para evaluar el papel de los milagros y la simbología involucrada. Se ha seguido entonces la construcción y resignificación de tres imágenes sagradas desde la forma en que fueron operando en la sociedad que las construyó, identificando apropiaciones y reapropiaciones.

En los tres cultos elegidos se evidenció una actuación del símbolo en términos integradores. Ya fuera por diferencias culturales o socioeconómicas, la eficacia simbólica (Turner y Levi-Strauss 
en Costilla 2012) pudo operar atenuando en una dimensión religiosa las tensiones sociales. Las relaciones entre vecinos criollos y comunidades indígenas en Copacabana, entre negros, indios, mestizos y criollos en Lima, o entre habitantes de una ciudad fragmentada socialmente por una crisis política y económica, en el caso de San Nicolás, podían tornarse vínculos trascendentes por acción de las imágenes sagradas, representadas como Madres, Patronas, Reinas o protectoras tradicionales. Así, en un plano simbólico-religioso se afirma el sentido de pertenencia que une a distintos grupos y los compromete en una comunidad cristiana y con una imagen hegemónica.

Volviendo ahora a la afirmación inicial, si la etnohistoria incluye una pregunta o mirada antropológica, debemos considerar la perspectiva metodológica en la especificidad de la antropología. Esto ya no tendría que ver tanto con las preguntas formuladas sino con la manera en que pueden responderse, empleando el "paradigma epistemológico de la antropología" (Lorandi 2012). Desde este punto de vista, la antropología es entendida como un saber construido in situ, basado en la experiencia y el acercamiento, como única ciencia social donde el investigador está involucrado en/ entre sus interlocutores (Wright 1998). Esta cuestión metodológica, reflejada en las entrevistas respecto de la etnohistoria argentina (Zanolli et al. 2010), continúa presente en las reflexiones actuales de los etnohistoriadores andinos, siendo la observación participante planteada como único medio posible para producir conocimiento antropológico (Platt 2013). La presencia de trabajo de campo -en su sentido tradicional de involucramiento del investigador con sus "nativos"- sería entonces condición excluyente para la definición de una investigación como antropológica.

Si es posible responder preguntas antropológicas sin recurrir a un trabajo de terreno, la etnohistoria parecería mantener su matriz antropológica; sin embargo ¿hasta qué punto el trabajo del etnohistoriador no involucra un trabajo de campo de tipo etnográfico? Descontando los trabajos que parten del presente (Abercrombie 2006; Wachtel 2001; entre otros), distintos etnohistoriadores han subrayado las similitudes entre el archivo y el campo, o del "archivo como acontecimiento de terreno" (Platt 2013), como así también la posibilidad de aplicar un enfoque etnográfico al estudio de los documentos. El archivo puede, de esta manera, volverse el campo del trabajo antropológico (Nacuzzi 2002) y los fenómenos históricos (mediatizados por el documento) las unidades acerca de las cuales se detiene la observación etnográfica (Boixadós 1994; Smietnianski 2010). En definitiva, la búsqueda del punto de vista nativo (Geertz 1994) sigue siendo el objetivo que guía estas indagaciones históricas con perspectiva antropológica.

En esta investigación, el estudio de los cultos fue abordado tanto desde un enfoque etnográfico de los documentos como a base de un trabajo de campo actual. Es decir, se recurrió a las técnicas de ambas disciplinas tanto para responder las preguntas antropológicas como para reconstruir los procesos históricos. Hemos definido así dos ejes de encuentro: el primero ligado a un enfoque histórico-antropológico, que atendió a la dimensión simbólica de representaciones, prácticas y discursos de índole religiosa y a su historicidad, a su anclaje en relaciones sociales concretas y en momentos históricos particulares; el segundo, un método histórico-etnográfico, donde se manifestaron las similitudes entre campo y archivo, reclamando ambos el mismo distanciamiento profesional y la misma necesidad de "exotizar" lo conocido y empatizar con lo desconocido.

Resta considerar, por último, otra perspectiva concerniente a la especificidad antropológica de la etnohistoria: aquella que carga las tintas en la cuestión étnica. Aquí lo "etno" remitiría principalmente a indígenas, o a sectores subalternos en el marco de una situación colonial o de relaciones de poder poscoloniales. Aun siendo etimológicamente errónea, es actualmente visible esta asociación de lo étnico a lo indígena y de la etnohistoria a la reconstrucción -basada en documentos y tradiciones orales-de la historia de los colonizados, con particular interés en su memoria histórica. Así entendida, la etnohistoria se configura como un campo temático a la vez que un campo disciplinar definido -historiográfico y antropológico- (Curatola 2012; Lorandi 2012; Zanolli et al. 2010). En los últimos años, esta perspectiva ha llevado, por ejemplo, a plantear una vocación crítica de los estudios etnohistóricos, entendidos como manifestación latinoamericanista de la crítica poscolonial (Boccara 2012). A este respecto, se ha señalado que mientras algunos discuten relativo a qué es o era la etnohistoria, otros toman la historia en sus manos. Por tanto, una de las nuevas tareas sería dialogar con esas historias alternativas; porque sería desde su condición específica que pueden aportar 
a la relectura del pasado-(presente) colonial y a la manera de reconstruirlo (Boccara 2012) ${ }^{3}$. Pero es claro que esto se vincula más a una tradición académica de atender a la voz y a la acción de los grupos colonizados, caracterizados por su alteridad étnica respecto de los colonizadores, que a una cuestión nominal o semántica. Si consideramos, por tanto, que lo "etno" no se reduce a lo indígena -ni a grupos subalternos-(cfr. Lorandi 2012; Zanolli et al. 2010) puede afirmarse que los estudios etnohistóricos estarían definidos por su enfoque en la dimensión étnica de las acciones más allá de actores indígenas. Incluso se ha planteado una etnohistoria "más allá de las etnías" (CIE 2011). Volveremos acerca de esta cuestión en el punto 4 para considerar las unidades de análisis.

Pasando ahora al campo institucional, estas discusiones relativas a lo étnico han influido en un pasaje terminológico que caracterizó la propia historia del equipo al que pertenecemos. En las últimas dos décadas quienes integran la Sección Etnohistoria (UBA) han ido propugnando una suerte de "sustitución" del término etnohistoria por el de antropología histórica ${ }^{4}$ para definir su práctica profesional ${ }^{5}$. En ese contexto, el posicionamiento disciplinar desde donde se parte (en un puente entre la etnohistoria y la antropología de la religión) responde a la propia trayectoria profesional: a una formación como antropóloga -en un ámbito académico específico-, a una especialización en el estudio de fenómenos religiosos y a una pertenencia institucional que se identifica como integrante de la Sección Etnohistoria de la UBA y como investigadora formada en este campo redefinido como antropología histórica. Retomamos aquí lo señalado por dos autores locales acerca de la tensión actual entre la necesidad de una interdisciplina y de cuestionar las clasificaciones rígidas dentro de las ciencias sociales y al mismo tiempo ciertas exigencias académicas para definir límites y establecer rótulos (Zanolli y Rodríguez 2004:91). Siendo así, se podría afirmar que esta investigación desarrolló una antropología histórica comparada de la religión, adscribiéndose un viraje nominal ya en marcha dentro del equipo.

Respecto entonces de las preguntas de investigación consideramos que el aporte principal de sus respuestas, como podré exponer en los apartados siguientes, ha sido brindar nuevas herramientas para analizar las relaciones sociales que subyacen a la constitución de un culto católico y a la conformación de identidades nacionales, locales o regionales. En algunas situaciones, ya sea por declaración oficial (Cabildo de Lima o Policía y Fuerza Naval de Bolivia, por ejemplo) o por construcción simbólica (la virgen de Copacabana en Bolivia o la del Rosario en San Nicolás) el accionar del símbolo religioso se vio acompañado de la construcción de patronazgos en torno a la imagen sagrada. En otras, estuvo ligado a las fuerzas irradiadoras y congregadoras de los santuarios como centros sagrados. Pero también el milagro en tanto símbolo ha estado vinculado a procesos de identificación colectiva. Por tanto, se concluye que la actuación del símbolo religioso se expresó en tres aspectos complementarios: imagen/ santuario/milagro.

Siguiendo esta triple cara del símbolo, analizar su papel en distintas historias particulares permitió formular nuevas hipótesis respecto del proceso que sigue la consolidación de un culto católico y postular un eje de gravitación simbólica sobre la base de ese proceso. En principio observamos que cada caso expresó un trayecto posible: el de Copacabana fue primero santuario, luego imagen y por último milagro; el de Lima comenzó por el Cristo, luego el milagro y tras él el santuario; y el de San Nicolás mostró un milagro inicial-la aparición-materializado luego en imagen y finalmente en santuario. Luego comprobé que el aspecto inicial de ese proceso marcaba el peso simbólico del culto: el santuario en Copacabana, con una marcada sacralidad local y una tradición prehispánica como centro de peregrinaje; la imagen del Cristo en Lima, con una procesión histórica que es el eje principal de la devoción; y el milagro en San Nicolás, siendo las apariciones y prodigios de la virgen el principal fundamento del culto $^{6}$. Debido a que solo un análisis comparativo podía llevar a estas conclusiones, se continúa con el segundo punto.

\section{Los marcos espaciales}

Situar las preguntas de investigación en distintos contextos se planteaba como relativamente novedoso dentro de la tradición de investigaciones etnohistóricas, donde los estudios mayormente se vuelcan a problemáticas localizadas en espacios y tiempos acotados. Con algunas excepciones -como el trabajo de Ortemberg (2004) relativa a simbología republicana- en el equipo de la Sección Etnohistoria las comparaciones no han solido abordarse desde una misma investigación, sino mediante una integración de estudios paralelos ${ }^{7}$. 
El desafío de encarar una comparación entre distintos casos implicó en principio mantener ciertos marcos que no dejaran de hacerla posible ${ }^{8}$; así, para poder equipararlos se eligieron cultos de una misma área geohistórica: el espacio sudamericano correspondiente al virreinato del Perú hasta 1776. Las diferencias, por su parte, derivaron de sus particularidades históricas y socioculturales: de sus momentos de surgimiento, sus rasgos sociopolíticos y sociodemográficos y del tipo de imagen implicada (dos vírgenes y un cristo). Contrastaban una ciudad que fue sede arzobispal y capital virreinal -con población multiétnica y alta presencia de afrodescendientes-, un pueblo de indios andino y una ciudad ubicada entre la región pampeana y el litoral argentino -con población hispano-criolla e inmigración italiana desde fines del siglo XIX-. La inclusión de este último culto, tan alejado de los otros, se hacía justamente en función de sus potencialidades para enriquecer la comparación.

Respecto de lo metodológico, ha sido una ventaja poder definir etapas de acuerdo con un mismo criterio e incluir las diversas historias en un mismo marco de análisis. Las periodizaciones que seguí comprendieron tres grandes momentos, definidos y subdivididos en los términos de cada caso: 1) surgimiento y consolidación, 2) desarrollo posterior y 3) vigencia actual. Dentro del primero, un aspecto común ha sido la posibilidad de distinguir tres dimensiones implicadas en el inicio de un culto: a) el origen de la devoción a una determinada imagen, que puede ser histórico o legendario; b) la creación del objeto de culto, es decir, la elaboración concreta de la imagen material; y c) la invención de una devoción, un proceso usualmente ligado a la Iglesia y que puede ser a posteriori. En las tres dimensiones resultaron significativas las equivalencias entre las historias particulares y una especie de "modelo" general de historias de apariciones y devociones, vinculado a patrones narrativos españoles (Christian 1991; Fogelman 2003; Salles-Reese 1997). Asimismo, profundizar comparativamente en estos surgimientos me condujo a identificar dos momentos en la producción de una imagen de culto: uno material y uno simbólico, destacándose este último por ser aquel donde se construye su verdadera identidad, con un significado y un mensaje concretos. Aunque estos procesos pueden coincidir, demostramos que su distinción posee implicancias centrales para el análisis histórico-antropológico de un culto católico. De esta manera, planteamos una lógica de interpretación común para los procesos de construcción de cultos católicos, algo que facilita la profundización del análisis comparativo -salvando distancias temporales y espaciales- y que, por otra parte, ha sido el resultado del propio análisis comparado de historias particulares.

El método resultó útil también para esclarecer procesos históricos singulares a partir de comprobar ciertas conexiones probables entre fenómenos y factores (cfr. Llamazares 2009). No para subsumir los casos en esas generalidades, sino para evaluar más minuciosamente las singularidades que cada contexto le imprimió al desarrollo de los cultos, usualmente ligados a elementos y actores comunes: fieles, sacerdotes, religiosos, laicos, autoridades políticas, periodistas y vecinos no devotos interviniendo respecto de un campo religioso donde se consagran imágenes, se legitiman milagros y se construyen santuarios. Tomando algunas variables iniciales -imágenes, milagros, santuarios, etc.- se analizó en contextos diferentes cómo operan en determinados procesos y dinámicas -la construcción de identidades, el uso de lo simbólico, el ejercicio del poder, etc.-, ponderando la influencia de variables contextuales concernientes a dichos efectos (cfr. Nohlen 1988).

Desde el punto de vista de una etnohistoria andina, abrir estas comparaciones resultó iluminador para evaluar al papel de las representaciones y prácticas andinas en la reproducción de cultos católicos. Un ejemplo de esto fueron las distintas situaciones observadas en la relación entre la producción de la imagen y su carácter milagroso; mientras que en Lima y San Nicolás los autores materiales permanecieron anónimos, cobrando relevancia la imagen o el milagro, respectivamente ${ }^{9}$, en Copacabana recibió gran atención el escultor nativo Tito Yupanqui -descendiente de la elite incaica-, llegando a compartir la sacralidad de su imagen: como epítome de este proceso, en los últimos años fue consagrado como primer beato boliviano y se presenta su historia como emulando al propio calvario de Jesucristo. Tomando este caso como ejemplo de sacralización paralela, he sugerido una vinculación con el principio de dualidad propio de la cosmovisión andina, con la complementariedad femenino/masculino que quedaría expresada en la relación virgen/escultor. Se abría así una nueva línea de indagación. 


\section{La dimensión temporal}

Vimos anteriormente que los casos elegidos correspondían a imágenes originadas en distintos momentos históricos y que, con la inclusión del tercer caso, la investigación se vio extendida hacia una etapa contemporánea. Esto se dio en sintonía con un corrimiento temporal que ya estaba presente en el equipo de la Sección desde los años noventa y entre algunos etnohistoriadores andinos (p. ej. Langer $2013)^{10}$. Pero la particularidad de la investigación estuvo en mantener los períodos previos como punto de partida, en una línea similar a los trabajos de Platt (1996, 1999); solo así se podría reconstruir la larga duración desde donde interpretar más cabalmente la trayectoria y coyunturas de cada culto. En este sentido, el trabajo podía constituir un avance en el conocimiento de los procesos que caracterizaron a la historia latinoamericana, en sus distintas etapas, a partir de un análisis enfocado en la dimensión religiosa de la vida social. En los casos de origen colonial, por ejemplo, los enfrentamientos en torno a las imágenes y espacios de culto hicieron palpable el lugar de lo religioso en el Ancien Régime, con expresiones concretas que ilustraron ese "régimen de cristiandad" 11 propio de las sociedades coloniales latinoamericanas.

Aunque trabajar en la larga duración representó uno de los mayores desafíos, el resultado esperado ameritó tomarlo en tanto auguraba la posibilidad de enriquecer la compresión de los cultos mediante las evidencias históricas. Solo reconstruyendo la trayectoria completa de los símbolos podemos visibilizar el largo proceso por el que fueron creados, consolidados, reproducidos y resignificados, evaluando los factores que posibilitaron la vigencia actual de los cultos ${ }^{12}$.

Respecto de esta vigencia, pudo constatarse en los tres casos una renovación de las ocasiones para actualizar los cultos. Mientras en Bolivia se observa un restablecimiento del relato evangelizador y un fortalecimiento de la memoria referido a la devoción andina a la llamada "Mamita del Lago", en Perú se rememora la protección del Cristo en la sociedad limeña y su carácter mestizo, expresado en los devotos y participantes de la procesión (afrodescendientes, criollos, indígenas, mestizos). Al mismo tiempo, en San Nicolás (Argentina) se construye una memoria del culto, anclándola en la historia local y regional, y se afirma un patronazgo de la imagen sobre la ciudad.
Pero contemplando ahora las historias completas, puede advertirse en Copacabana que una imagen mariana tallada hacia fines del siglo XVI por un descendiente de la elite incaica es hoy celebrada con grupos de cumbia y se ha vuelto símbolo de la población boliviana migrante. También es presentada como símbolo de una nación y de un Estado: aunque su reconocimiento como tal no se extiende al interior del país de la manera en que es percibido desde afuera, es un hecho que pudo anclarse históricamente tanto en su declaración oficial como patrona simbólica de Bolivia a comienzos del siglo XX como en su apropiación por parte de la colectividad migrante en las últimas cuatro décadas. Su larga trayectoria mostró que los usos de los que ha sido objeto y la forma en que ha actuado en la sociedad se vinculan a su capacidad de expresar tradiciones andinas, con rasgos nativos en tanto imagen elaborada y significada localmente. Un proceso similar se observó para el Cristo limeño, donde una imagen pintada por un negro a mediados del siglo XVII es hoy venerada solemnemente por distintos sectores y poderes de la sociedad limeña y por la población peruana migrante ${ }^{13}$. Es igualmente reconocida como símbolo de la identidad nacional y como devoción asociada a dos tradiciones étnicas; pero, a diferencia del caso boliviano, ésta ha tenido una mayor extensión como referente identitario dentro de la sociedad peruana.

Por su parte, en San Nicolás, una imagen mariana traída desde Italia a fines del siglo XIX fue convertida en símbolo congregador desde 1983, llamando la atención el hecho de haber surgido su culto tras un siglo de permanecer la imagen en la ciudad y el haber crecido de manera exponencial en tan solo 25 años. Este surgimiento tardío se evidencia en la práctica nativa de celebrar desde esa fecha (1983) el "cumpleaños" de la Virgen; pero retrotraer su origen hacia el momento de la llegada de la imagen a la ciudad (1884) nos permitió profundizar en el papel de este símbolo en la sociedad nicoleña, entre autoridades políticas, Iglesia católica y elites locales. Lo llamativo aquí también fue que esa presencia local de la imagen, e incluso de la advocación del Rosario -desde tiempos coloniales-, no derivó en la construcción de un símbolo representativo de una identificación local o regional. La tesis desprendida fue que las circunstancias históricas en las que surgen los cultos condicionan notablemente la manera en que sus símbolos pueden operar en la sociedad en términos identificatorios. Distinguimos entonces 
aquellos que tuvieron una larga tradición relacionada con una idiosincrasia local de aquellos con un surgimiento reciente, más ligados al peregrino y al carácter ecuménico del cristianismo.

\section{Las unidades de análisis}

Como anticipamos en el punto 1 , el aspecto que singulariza a esta investigación es su apertura hacia distintos actores sociales, integrándose en una línea de trabajos locales más cercana a la tradición francesa de la antropología histórica. Mientras que en países como Perú, Bolivia, Chile y Ecuador, las investigaciones etnohistóricas continúan focalizadas mayormente en la problemática indígena y las sociedades campesinas (Hidalgo et al. 2013), la Sección Etnohistoria de la UBA integra una gran variedad de temas donde las elites hispano-criollas cobran protagonismo (cfr. Zanolli et al. 2010).

En ese marco, la investigación se propuso focalizar no ya en grupos sociales específicos sino en los fenómenos religiosos entendidos como hechos sociales polisémicos. De esta manera, la indagación se detiene en los cultos como unidades de análisis para estudiar al símbolo religioso, particularmente al milagro como construcción social.

Pero llevar el foco al fenómeno ¿no implica despersonalizarlo o abstraerlo de la realidad social? Teniendo en cuenta que son los propios actores sociales los que lo construyen y reproducen, el foco debería estar en ellos y no en el símbolo en sí; sin embargo, aquí este se vuelve la vía de entrada para el análisis de lo social en relación con su heterogeneidad y a las tensiones entre grupos. Para estudiar una sociedad colonial o actual con sus diferencias culturales, étnicas, económicas, etc., puede abordarse un signo multiacentuado entendido como "arena de la lucha de clases" (cfr. Volóshinov 2009[1929]:47); y si la forma más cabal de comprenderlo es analizando esos diversos grupos que se lo apropian, entender cómo se posiciona cada grupo frente al símbolo permite entender también las relaciones entre ellos. Desde el momento en que se lo comprende como parte de un campo social y material, el símbolo deja de ser una entidad abstracta para volverse una materialidad expresada en prácticas y discursos concretos.

En relación con el milagro hemos podido confirmar que, en tanto símbolo, se constituye como un elemento pasible de generar y canalizar diversos significados. Así, cualquier hecho interpretado eclesiástica o devocionalmente como milagro -como signo de una intervención sagrada-, puede ser estratégicamente esgrimido desde distintos actores sociales. En los tres cultos, no solo la Iglesia como institución sino actores ajenos a ella, tanto dentro como fuera del campo religioso, mostraron recurrir a las imágenes milagrosas -y a los propios hechos prodigiosos- para fines diversos.

Atendiendo a estos usos estratégicos comunes, además de la esperable apropiación de los símbolos religiosos en un sentido evangelizador, en términos político-eclesiásticos han sido esgrimidos en carácter reivindicatorio y especialmente de manera consagratoria y fundacional: es ejemplar en este punto el caso de Copacabana, con un santuario creado por los agustinos en el período colonial y un cerro (el Calvario) cristianizado por los franciscanos a mediados del siglo XX. Ambos usos, a su vez, se expresaron como estrategias de empoderamiento de órdenes religiosas particulares, de las Iglesias diocesanas frente a otras diócesis $-\mathrm{O}$ a la propia curia romana-, o de la Iglesia católica frente a otras confesiones.

En términos devocionales y sociopolíticos, el caso de Copacabana mostró que la población nativa (especialmente autoridades étnicas) ha recurrido al símbolo religioso como herramienta para resacralizar un espacio tradicional, para la obtención de reconocimiento, para legitimar su lugar como cristianos y para garantizar el acceso a ciertos espacios y beneficios. Concentrados estos usos nativos dentro de la etapa colonial, se expresa la relevancia que los símbolos religiosos tenían en ese contexto, a diferencia de etapas posteriores con otras herramientas de lucha. Otro sector étnicamente subalterno han sido, en el caso de Lima, los afrodescendientes, cuya eficaz apropiación del símbolo pudo evidenciarse en el mantenimiento de una cofradía hasta hoy, por encima de las intervenciones oficiales. Con la Virgen de San Nicolás, en cambio, más allá de su apropiación por parte de trabajadores locales desocupados -al privatizarse la gran empresa radicada en la ciudad: SOMISA (cfr. Costilla 2013)-, no se registraron usos devocionales en términos arraigados en una cosmovisión local o en grupos sociales particulares.

Las apropiaciones de autoridades políticas republicanas, al igual que las de autoridades seculares coloniales, se dieron -exceptuando las primeras décadas de gobiernos republicanos durante el siglo XIX- en términos de mutua 
legitimación y consagración. A su vez coincidieron con la autoridad eclesiástica en torno al uso del símbolo desde dos sentidos ajenos al campo religioso: el patrimonial y el turístico. Debido a que la apropiación en términos de patrimonialización solo fue evidente en las últimas etapas de los cultos, pudo ser planteada como expresión de un uso político de lo religioso propio del siglo XX. Por lo demás, fue compartido por Iglesia y autoridades políticas el recurso estratégico al símbolo religioso desde intereses político-económicos en el plano turístico.

En todos estos ejemplos, aunque es posible referirse a actores colectivos, en definitiva hemos partido siempre de las acciones concretas de agentes individuales: curacas, vecinos, virreyes, fieles, religiosos, sacerdotes, gobernadores, cofrades, laicos, presidentes, arzobispos. Consideramos así que en este punto el trabajo aporta a la discusión respecto del carácter social e individual de los fenómenos religiosos. Destacar la dimensión social y colectiva de la devoción religiosa no fue incompatible con una consideración especial respecto del lugar del sujeto en la construcción, actualización y recreación del culto. Los fenómenos religiosos no pueden ser entendidos solo como hechos sociales, porque la religión es, ante todo, un hecho humano de implicancias subjetivas (Costilla 2012). Así, fue a partir de los propios participantes de estas celebraciones, de sus voces, sus experiencias y sus comportamientos materializados en las fuentes consultadas y en los testimonios recogidos que se recorrió la historia y los significados de cada devoción.

\section{A modo de conclusión}

En el ámbito de la UBA, la etnohistoria fue constituyéndose dentro del área institucional de la antropología, pero en relación con una tradición de estudios donde confluyeron varias disciplinas (entre ellas, la antropología y la historia). La identidad disciplinar que fuimos configurando a lo largo de la formación profesional en ese espacio académico ha estado entonces ligada al desarrollo de la etnohistoria a nivel regional, al anclaje antropológico de la Sección Etnohistoria y a los propios virajes dentro de este equipo argentino, especialmente aquellos que habían dado lugar al pasaje terminológico de una etnohistoria a una antropología histórica.

Aunque el tema de investigación fue definiéndose en ese marco institucional y académico, supo también abrir nuevos caminos en el horizonte de la etnohistoria, tanto en su línea entroncada con los estudios andinos como en relación con las investigaciones del equipo de la UBA. A nivel espacial, temporal y temático, el problema de investigación trabajado presentó su singularidad frente a las tradiciones de la etnohistoria latinoamericana. Con un abordaje centrado en los cultos religiosos como unidades de análisis, un marco teórico nutrido por la antropología simbólica y un enfoque orientado a reconstruir perspectivas "nativas" del campo religioso, propusimos contribuir al desarrollo de una antropología histórica comparada de procesos sociorreligiosos en Latinoamérica.

En lo personal, y a propósito de esa constante tensión entre rechazar los rótulos y caer en ellos forzosamente debido a requerimientos institucionales (Zanolli y Rodríguez 2004), pienso que a la hora de definir mi práctica de investigación la mejor forma de describirla es refiriendo a una antropología histórica de la religión, aun cuando esa definición parezca chocar con la condición de integrante de la Sección "Etnohistoria". En este sentido consideramos que al menos en el ámbito de la UBA, la etnohistoria ha mantenido a lo largo de los últimos 25 años una flexibilidad que le ha permitido traspasar distintos recortes y definiciones sin perder su singularidad como campo de estudios particular.

\section{Agradecimientos}

A mis colegas de la Sección Etnohistoria, especialmente a Carlos Zanolli, Alejandra Ramos y Dolores Estruch. A los coordinadores del simposio "Diversidad y posibilidades en las etnohistorias andinas", del IX Congreso Internacional de Etnohistoria y a los evaluadores anónimos de este manuscrito. 


\section{Referencias Citadas}

Abercrombie, T.

2006 Caminos de la Memoria y el poder. Etnografía e Historia en una Comunidad Andina. IFEA, IEB, Asdi, La Paz.

Avellaneda, M.

1999 Estrategias del conflicto Cárdenas-jesuitas por el control de las Reducciones en el Paraguay. En Un reino en la Frontera. Las Misiones Jesuitas en la América Colonial, coordinado por S. Negro y M. Marzal, pp. 73-94. PUCP \& ABYA-YALA, Lima/Quito.

Bloch, M.

2006 [1924] Los reyes Taumaturgos: Estudio sobre el Carácter Sobrenatural Atribuido al poder real, Particularmente en Francia e Inglaterra. FCE, México.

1952 Introducción a la Historia. FCE, México.

Boccara, G.

2012 ¿Qué es lo "etno" en etnohistoria? La vocación crítica de los estudios etnohistóricos y los nuevos objetivos de lucha. Memoria Americana 20-1 [en línea].

Boixadós, R.

1994 Fundaciones de ciudades como rituales. Análisis de tres casos en el contexto de la conquista del Tucumán colonial. Anuario Antropológico 92: 145-178. Universidad de Brasilia.

Bouysse-Cassagne, $\mathrm{T}$.

1997 De Empédocles a Tunupa: Evangelización, Hagiografía y Mitos. En Saberes y Memorias en los Andes. In Memorian Thierry Saignes, editado por T. Bouysse-Cassagne, pp. 157212. IHEA, IFEA, Lima.

Brow, J.

1990 Notes on Community, Hegemony, and the Uses of the Past. Anthropological Quarterly 63 (1):1-7. [traducido por cátedra Golluscio. FFyL, UBA. 1999]

Christian, W.

1991 Religiosidad local en la España de Felipe II. Nerea, Madrid.

Costilla, J.

2012 Luchas hermenéuticas y usos estratégicos del milagro: perspectivas desde la antropología y la sociología de la religión. En Entre Pasados y Presentes III. Estudios contemporáneos en ciencias antropológicas, compilado por N. Kuperszmit, T. Lagos Mármol, L. Mucciolo, M. Sacchi, pp. 283-303. Editorial MNEMOSYNE, Buenos Aires.

2013 El culto a la Virgen del Rosario en San Nicolás de los Arroyos (Argentina, 1983-2010): milagro y reconfiguración social. Runa 34(a):177-195. ICA, FFyL, UBA, Buenos Aires.

Estenssoro Fuchs, J.C.

2003 Del Paganismo a la Santidad: la Incorporación de los Indios del Perú al Catolicismo, 1532-1750. IFEA, Lima.

2005 Construyendo la memoria: la figura del inca y el reino del Perú, de la conquista a Tupac Amaru II. En Los Incas, Reyes del Perú, coordinado por N. Majluf. Banco de Crédito, Lima.

Estruch, D.

2008 Rastros de una ausencia, rastros de una presencia. La Compañía de Jesús en el Jujuy colonial. 1593-1759. En Historia social de la Conversión: La Compañía de Jesús en la Argentina, compilado por C. Paz y E. Cruz. Purmamarka Ediciones, Jujuy.

Fogelman, P.

2003 Reconsideraciones sobre los orígenes del culto a la Virgen de Luján. Entrepasados 23:123-148. Buenos Aires.
Geertz, C.

1994 Conocimiento local: Ensayos sobre la Interpretación de las Culturas. Paidós, Barcelona.

Gruzinski, S.

1991 La Colonización de lo Imaginario. Sociedades Indígenas y Occidentalización en el México Español. Siglos XVI-XVIII. FCE, México.

Hidalgo, J., N. Castro y J. Aguilar

2013 Historia de los pueblos andinos de Arica, Tarapacá y Atacama. En Los Estudios Andinos Hoy: Práctica Intelectual y Estrategias de Investigación, compilado por C. Zanolli, J. Costilla, D. Estruch y A. Ramos, pp. 243-276. Prohistoria, Rosario.

Langer, E.

2013 Creando la etnohistoria de los siglos XIX y XX. En Los Estudios Andinos Hoy: Práctica Intelectual y Estrategias de Investigación, compilado por C. Zanolli, J. Costilla, D. Estruch y A. Ramos, pp. 278-290. Prohistoria, Rosario. Llamazares Valdueco, I.

2009 Método comparativo. En Diccionario Crítico de Ciencias Sociales, dirigido por R. Reyes. Plaza y Valdés, Madrid.

Lorandi, A.M.

2012 ¿Etnohistoria, Antropología Histórica o simplemente Historia? Memoria Americana 20-1 [en línea].

Lorandi, A.M. y A.E. Schaposchnik

1990 Los milagros de la Virgen del Valle y la colonización de la ciudad de Catamarca. Journal de la Société des Américanistes 76:177-198. París.

Mujica Pinilla, R.

2001 Rosa Limensis. Mística, Política e Iconografía en torno a la Patrona de América. IFEA, FCE, Banco Central de Reserva del Perú, Lima.

Nacuzzi, L.

2002 Leyendo entre líneas. En Historia y Estilos de Trabajo de campo en la Argentina, compilado por S. Visacovsky y R. Guber. Antropofagia, Buenos Aires.

Nacuzzi, L.R., C.P. Lucaioli y F.S. Nesis

2008 Pueblos Nómades en un Estado Colonial. Chaco, Pampa, Patagonia, Siglo XVIII. Antropofagia, Buenos Aires.

Ortemberg, P.

2000 Celebraciones del poder real en Lima: itinerarios teórico-metodológicos. Memoria Americana 9:91-114. Sección Etnohistoria, FFyL, UBA, Buenos Aires.

2004 Algunas reflexiones sobre el derrotero social de la simbología republicana en tres casos latinoamericanos. La construcción de las nuevas identidades políticas en el siglo XIX y la lucha por la legitimidad. Revista de Indias LXIV (232): 697-720. CSIC, Madrid.

Nohlen, D.

1988 Método comparativo. En Terminología Científico-Social, editado por R. Reyes. Anthropos, Madrid, s.p. http://www. rzuser.uni-heidelberg.de/ k95/es/doc/diccionario_metodocomparativo.pdf (14 febrero 2010)

Platt, T.

1996 Los Guerreros de Cristo. Cofradías, misa solar, y guerra Regenerativa en una Doctrina Macha (siglos VIII-XX). ASUR - Plural, La Paz.

1999 La Persistencia de los ayllus en el norte de Potosí: de la Invasión Europea a la República de Bolivia. Fundación Diálogo, La Paz. 
2013 Entre la rutina y la ruptura: el archivo como acontecimiento de terreno. En Los Estudios Andinos Hoy: Práctica Intelectual y Estrategias de Investigación, compilado por C. Zanolli, J. Costilla, D. Estruch y A. Ramos, pp. 217-242. Prohistoria, Rosario.

Quarleri, L.

1999 Los jesuitas en La Rioja colonial: la adquisición de las tierras, los conflictos con la sociedad local y la gestión de la Junta de Temporalidades (1624-1812). Actas del Congreso Internacional Jesuitas 400 Años en Córdoba Tomo II, pp. 341-367. Junta Provincial de Historia de Córdoba.

Quarleri, L.y A.M. Lorandi

2009 Los cabildos en perspectiva comparativa. El territorio misionero del Paraguay colonial y el espacio andino. Actas del Taller Andes y Amazonas y sus Transformaciones: Comparaciones, Conexiones, Fronteras entre las Tierras Altas y Bajas de Sud América, editado por T. Platt, G. Rivière e I. Daillant. University of Saint Andrews.

Reynoso, C.

1998 Corrientes en Antropología Contemporánea. Biblos, Buenos Aires.

Rostworowski, M.

1992 Pachacamac y el Señor de los Milagros. Una Trayectoria Milenaria. IEP, Lima.

Salles-Reese, V.

1997 From Viracocha to the Virgin of Copacabana. University of Texas, Austin.

Smietnianski, S.

2007 El juicio de residencia como ritual político en la colonia (Gobernación de Tucumán, Siglo XVIII). Memoria Americana 15:71-101. Sección Etnohistoria, FFyL, UBA, Buenos Aires.
2010 De preeminencias, estilos y costumbres: rituales y poder en los cabildos coloniales. Una aproximación etnográfica al análisis de materiales de archivo. Revista Colombiana de Antropología 46 [en línea].

Sturtevant, W.C.

1966 Anthropology, History, and Ethnohistory. Ethnohistory 13 (1-2): 1-51.

Volóshinov, V.N.

2009 [1929]. El Marxismo y la Filosofía del Lenguaje. Godot, Buenos Aires.

Wachtel, N.

2001 El regreso de los antepasados. Los Indios Urus de Bolivia, del Siglo XX al XVI. FCE, México DF.

Wilde, G.

2003 Poderes del ritual y rituales del poder: un análisis de las celebraciones en los pueblos jesuíticos de guaraníes. Revista Española de Antropología Americana 33: 203-229. Universidad Complutense, Madrid.

Wright, P.

1998 Etnografía y existencia en la antropología de la religión. Sociedad y Religión 16/17: 180-193. CEIL-CONICET, Buenos Aires.

Zanolli, C. y L. Rodríguez

2004 La antropología histórica: entre la tradición académica y las prácticas de investigación. Historia Indígena 8: 89-100. Universidad de Chile.

Zanolli, C., A. Ramos, D. Estruch y J. Costilla

2010 Historia, Representaciones y Prácticas de la Etnohistoria. Una Aproximación Antropológica a un Campo de Confluencia Disciplinar. Antropofagia, Buenos Aires.

Zanolli, C., J. Costilla, D. Estruch y A. Ramos (comps.)

2013 Los Estudios Andinos Hoy: Práctica Intelectual y Estrategias de Investigación. Prohistoria, Rosario.

\section{Notas}

1 Los tres reunían varias características básicas: extensión en el tiempo y vigencia actual; magnitud y extensión (espacial y temporal) de la devoción; existencia de material para investigar su origen y desarrollo; presencia de milagros y disponibilidad de documentación para analizarlos; vinculación con procesos de construcción de identidades y de apropiación por parte de diversos actores.

2 Los trabajos de María de Hoyos (por ejemplo: Vigencia de prácticas Funerarias Precolombinas entre Poblaciones Campesinas. Actas del I Congreso Latinoamericano de Folklore, 1996) abordan aspectos simbólicos y rituales pero en relación con prácticas prehispánicas vinculadas al arte rupestre.

3 La cuestión no sería entonces saber qué es la etnohistoria sino cómo funciona (Trouillot en Boccara 2012): esto es, cuáles son las condiciones de producción de las narrativas y cómo las relaciones de poder actuales determinan las representaciones del pasado.

4 Tomada en el sentido otorgado por Le Goff (historiador) o Goody (antropólogo), la antropología histórica serviría para interrogarnos acerca de la estructura cultural de cualquier segmento social privilegiando el análisis de los hábitos, las actividades y los imaginarios desde una perspectiva antropológica (Lorandi 2012). Combinando, por una parte, el análisis de la estructura social con el de los acontecimientos $y$, por otra, los enfoques en escalas micro y macro, se estudian las representaciones simbólicas y las prácticas significativas de una sociedad o grupo desde el sentido que ellos mismos le otorgan. Influencias que contribuyeron a este nuevo enfoque han sido la microhistoria y autores como Marshall Sahlins, Jean y John Comaroff, Anthony Giddens y Pierre Bourdieu.

5 Respecto de este tema hemos avanzado en Zanolli et al. 2010.

6 Esta gravitación pudo contrastarse en los actos de reconocimiento a las imágenes, en los discursos y prácticas en torno a la atracción de visitantes y peregrinos a los santuarios y ante todo en las fechas celebratorias de cada culto: la de Copacabana -2 de febrero- conmemorando la llegada de la imagen; las de Lima $-18,20$ y 28 de octubre-, fundamentadas en las procesiones con la imagen correspondientes a los sismos más recordados; y la de San Nicolás -25 de septiembre- señalando el día de la primera aparición.

7 Un ejemplo es la compilación relativas a tierras bajas donde se confrontaron experiencias y procesos del Chaco austral, la Pampa y la Patagonia argentinos (Nacuzzi et al. 2008). Allí, recuperando la tradición historiográfica 
iniciada por Bloch (2006 [1924]) pero desde el punto de vista de la etnohistoria, se logró debatir diversos estudios acerca de grupos indígenas nómades $-\mathrm{y}$ sus relaciones con la sociedad hispanocriolla-. Otras comparaciones se han propuesto entre tierras altas y bajas, como el trabajo de los cabildos del Paraguay colonial y el espacio andino (Quarleri y Lorandi 2009), integrado en una compilación de Andes y Amazonas.

8 Dentro de la antropología el análisis comparativo ha sido históricamente aplicado -y también cuestionado-desde diversas corrientes teóricas y bajo el influjo de distintos paradigmas (cfr. Reynoso 1998). Con sus aciertos y desaciertos, cada aproximación permitió ir avanzando en el conocimiento de las ventajas de este método para la disciplina.

Como señalamos en el punto 1, en Lima fue el mural del Cristo, por su conservación, el que recibió una mayor carga de sacralidad; mientras que en San Nicolás se destacó el milagro, por tratarse de apariciones previas a la presencia de una imagen de culto que las representara.

10 con procesos nacionales, etc.) los investigadores comenzaron

a extenderse hacia la historia republicana y del siglo XX. Esto se vio influido también por los nuevos sentidos que fue adquiriendo la dimensión temporal de la etnohistoria: la relación entre pasado y presente fue repensándose a partir de trabajos que materializaron el planteo original de Bloch (1952) de una historia regresiva (Abercrombie 2006; Wachtel 2001; entre otros).

11 Cfr. Di Stéfano y Zanatta 2000; Estruch 2009.

12 Es destacable subrayar que construir esas trayectorias implicó deconstruir otras previamente armadas y relatadas. Contar entre las fuentes con crónicas cuyos objetivos eran narrar la historia del culto ha sido una ventaja, desde ya, pero también un desafío, en tanto debió enfrentarse la tentación de tomarlas como válidas. La tarea consistió de esta manera en compulsar y reordenar distintos "retazos" de historia.

13 Por ello postulamos dos niveles de mestizaje en torno a la imagen: uno asociado a sus raíces afroamericanas y otro advertido en sucesivas reapropiaciones del culto por parte diversos sectores socioétnicos y agentes de la sociedad local (fieles, laicos, religiosos, autoridades, etc.). 
